\title{
Study on the Model of Relationship between Manufacturing Green Supply Chain and Enterprise Green Behaviors
}

\author{
Zhi-Ping LU ${ }^{1, a}$, Lv LV ${ }^{2, b, *}$ \\ ${ }^{1,2}$ School of Management, Guangxi University of Science and Technology, P. R. China \\ a404840561@qq.com, ${ }^{b} 527534542 @ q q . c o m$ \\ ${ }^{*}$ Corresponding author
}

Keywords: Green supply chain, Enterprise green behaviors, ANP.

\begin{abstract}
This paper erected a model of relationship between manufacturing green supply chain and enterprise green behaviors by using the Analytic Network Process theory. We took Guangxi province as an example. With the help of Analytic Network Process and related software data statistics, we draw out the effect of enterprise green behaviors with respect to implement green supply chain Management. And we analyze the reasons for this situation and put forward countermeasures and suggestions.
\end{abstract}

\section{Introduction}

In the 21 st century, we need to change the traditional manufacturing methods to ease the conflict between human and the nature, and achieve the sustainable development of enterprises. Green supply chain management is one of the effective innovative ways. For some regions and provinces in which manufacturing industries still lag behind, implement green supply chain management is imperative in order to make full use of the late-development advantage and to stand out in the industry in the future. Based on such a background, we built a relational model of enterprise green supply chain and enterprise green behaviors in the use of analytic network process theory (ANP). And then take Guangxi as an example. This method and the relational model shall have widespread applicability in other regions and provinces.

\section{The Conceptual Model}

\section{Green Supply Chain}

National Science Foundation is the first one who proposed the concept of green supply chain in the study of environmentally responsible manufacturing in 1996 [1]. However, there is no authoritative and unified definition on the concept. Steven V. Walton believes that green supply chain management is adding the vendors to the company's environmental strategy. Its core is applying the integrative management thought to green supply chain [2]. Chinese scholars are more likely to make researches of green supply chain with a manufacturing perspective. Take Dan Bin as an example, he holds that green supply chain is a modern management model which takes the environmental impact and comprehensive effectiveness into consideration throughout the supply chain, It designs suppliers, manufacturers, vendors and users, in order to minimize the negative effect with respect to the environment and maximize the resource efficiency [3].

From the above discussion, we divide the manufacturing green supply chain into three subsystems, production subsystem, environment subsystem and consumer subsystems. For the traditional manufacturing industry, what the companies mostly consider about must be economic performance. Environment subsystem includes the provision of resources, the recycling and reuse of products, the waste disposal. This subsystem efficiency can be measured by environmental performance. Consumer subsystem refers to the whole consumer products consumption process, and consumer welfare is available to measure the subsystem efficiency. 
In summary, the three potential principles contacting green supply chains and enterprise green behaviors are economic performance (P1), environmental performance (P2) and consumer welfare (P3).

\section{Enterprise Green Behaviors}

There is still no authoritative and unified classification on Enterprise Green Behaviours. Sarkis divided the environmental behaviours which enterprises engaged in into the environmentally friendly research and development, life cycle analysis, total quality management basing on environment, green supply chain management and the adoption of ISO14000 standard [4]. The Five Positive Environmental Management Measures proposed by Berry and Rondinelli contain waste reduction, customer demand management, environment-friendly technology design, product management and environmental accounting. This idea reflects the systematic management thinking on crossing the function and the enterprise boundaries [5].

Basing on the current development of China's manufacturing industry, this study classified the major enterprise green behaviors companies involved in to four clusters. The result is shown in table 1.

Table 1 Enterprise green behaviors

\begin{tabular}{|c|c|}
\hline Clusters & Element nodes \\
\hline $\begin{array}{l}\text { Green procurement } \\
\mathrm{C}_{1}\end{array}$ & Choosing green suppliers $e_{11}$ \\
\hline \multirow{2}{*}{$\begin{array}{c}\text { Green manufacturing } \\
\mathrm{C}_{2}\end{array}$} & Green product design $e_{21}$ \\
\hline & Green production $\mathrm{e}_{22}$ \\
\hline \multirow{4}{*}{$\begin{array}{l}\text { Green marketing } \\
\mathrm{C}_{3}\end{array}$} & Promoting green consumption $\mathrm{e}_{31}$ \\
\hline & Green pricing $\mathrm{e}_{32}$ \\
\hline & Establishing green distribution channels $\mathrm{e}_{33}$ \\
\hline & Green product promotions $\mathrm{e}_{34}$ \\
\hline \multirow{3}{*}{$\begin{array}{c}\text { Green logistics } \\
\mathrm{C}_{4}\end{array}$} & Green transportation $\mathrm{e}_{41}$ \\
\hline & Green packaging $\mathrm{e}_{42}$ \\
\hline & Green recycling $\mathrm{e}_{43}$ \\
\hline
\end{tabular}

\section{Conceptual Model}

Basing on analytic network process (ANP) theory, we establish a relationship model. The model is divided into control layer and network layer. The control layer takes green supply chain comprehensive performance as the goal, economic performance, environmental performance and consumer welfare as three criterions. These three criterions at control layer are independent one another, so their weights can be obtained by traditional Analytic Hierarchy Process (AHP) method. The network layer contains green procurement, green manufacturing, green marketing and green logistics as four clusters which were mentioned above. These clusters contain a variety of Enterprise Green Behaviours as element nodes which were interactive and interdependent each other. The whole model reflects influences on green supply chain manufacturing which the various Enterprise Green Behaviours make. The Conceptual model is shown as Figure.1.

\section{The Mathematical Model}

The Analytic Network Process method is known as three steps. Firstly, set up the network structure mode. Secondly, set up the un-weighted super matrix, weighted super matrix and Limit Matrix. Thirdly, get the overall Priorities.

As involving with the super-matrix, ANP method is quite complicated. In fact, we can simplify the theoretical procedures with the help of Supper Decisions software [6]. We take Guangxi as an example to show you the way. 


\section{ANP Network Establishment}

According to the conceptual model, we can established a network structure model which includes clusters, element nodes and the relationship, by using a series of commands such as "Cluster, Node, Node connections" in Supper Decisions software menu. The ANP network structure is shown in Figure.2.

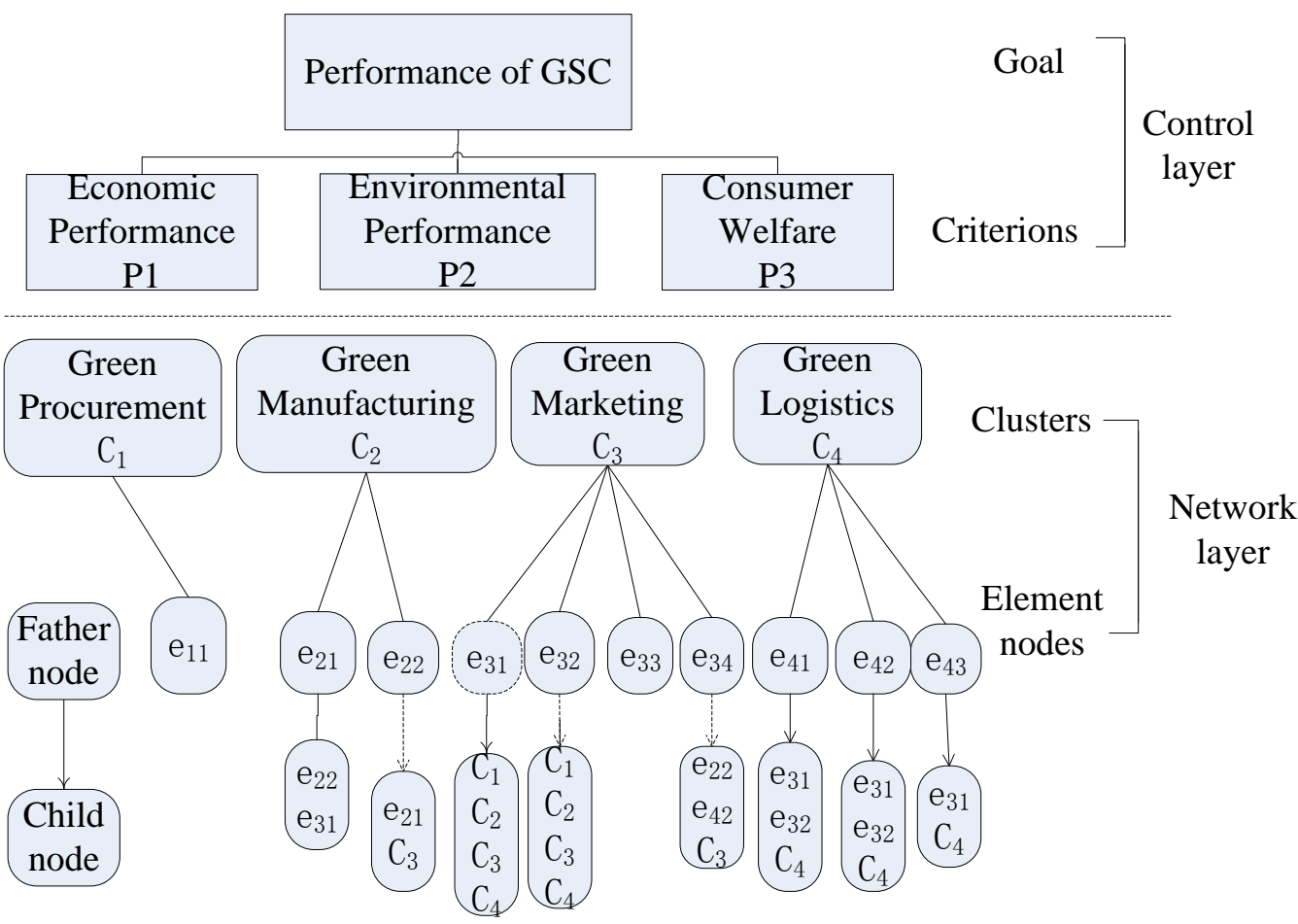

Figure 1 Conceptual Model of GSC and enterprise green behaviors.

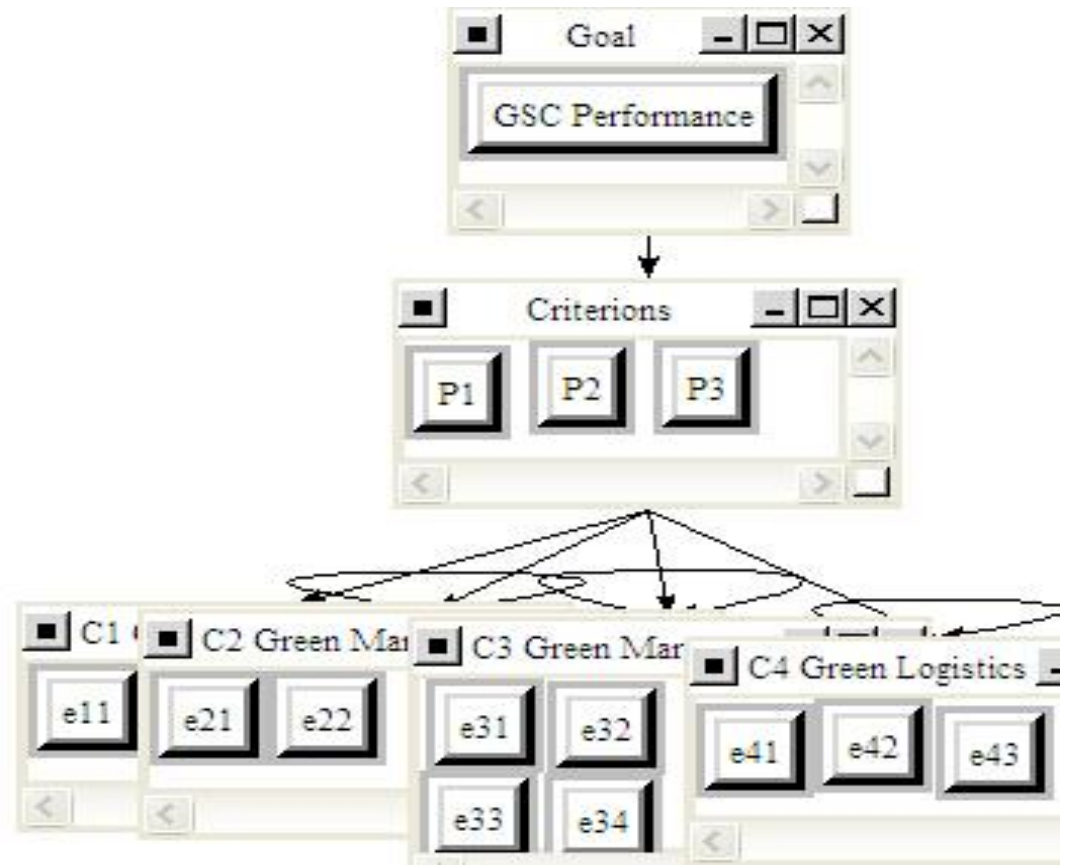

Figure 2 ANP network structure in supper decisions software.

\section{Un-weighted, Weighted, Limit Matrix and Priorities}

The data is from five university scholars and five Guangxi manufacturing supply chain management practitioners. Now we take one of these personal evaluative data to give an explanation. 
By using the " $a<b$ " command you can input the element nodes comparative data. We take green supply chain performance as a criterion, take the economic performance as the subordinate criterion, and take the elements nodes in green logistics cluster to compare their impact, and then we can get the judgment matrix. The result is shown in Figure.3. The consistency index value CR is less than 1, which passed the consistency test, so the normalized weight vector is acceptable. Due to space limitations, we do not show the consistency test here.

After inputting all the judgment data of element nodes (both pass the consistency test), you can get the un-weighted matrix by using the command "Un-weighted Super Matrix" in the computations menu. Due to space limitations, we do not show the Un-weighted Super Matrix here.

By using the " $\mathrm{A}<\mathrm{B}$ " command you can input the clusters comparative data. The procedure is the same as the input of element nodes comparative data we mentioned above. After that, you can get the weighted matrix by using the command "Weighted Super Matrix" in the computations menu. Due to space limitations, we do not show the Weighted Super Matrix here, either.

You can get the Limit Matrix and Priorities by using the command "Limit Matrix" and "Priorities" in the computations menu. Due to space limitations, we do not show the Limit Matrix. And the Priorities are shown in Figure 4.

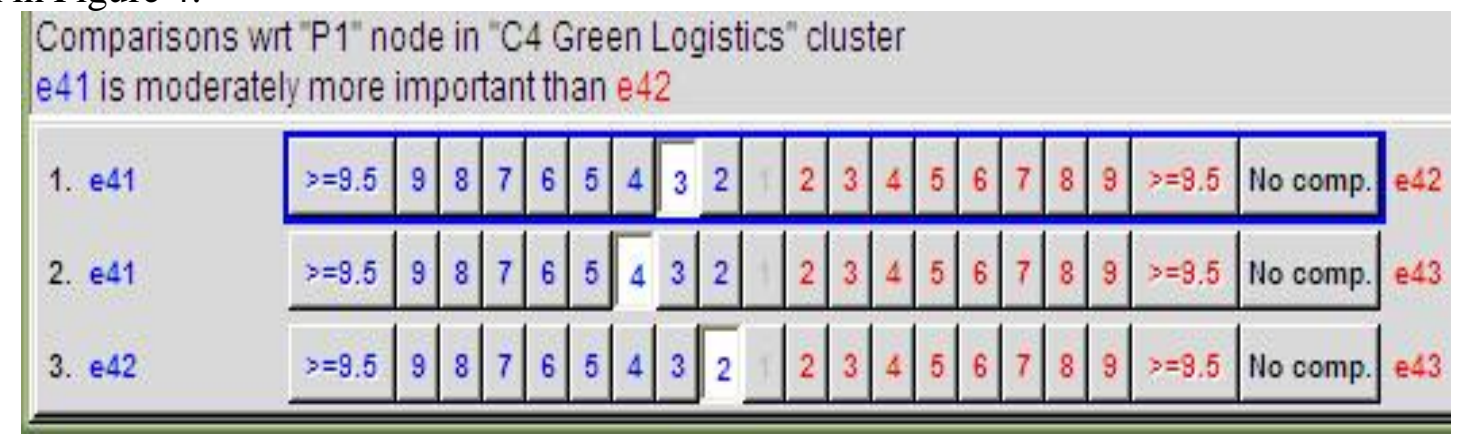

Figure 3 The judgment matrix in Supper Decisions software.

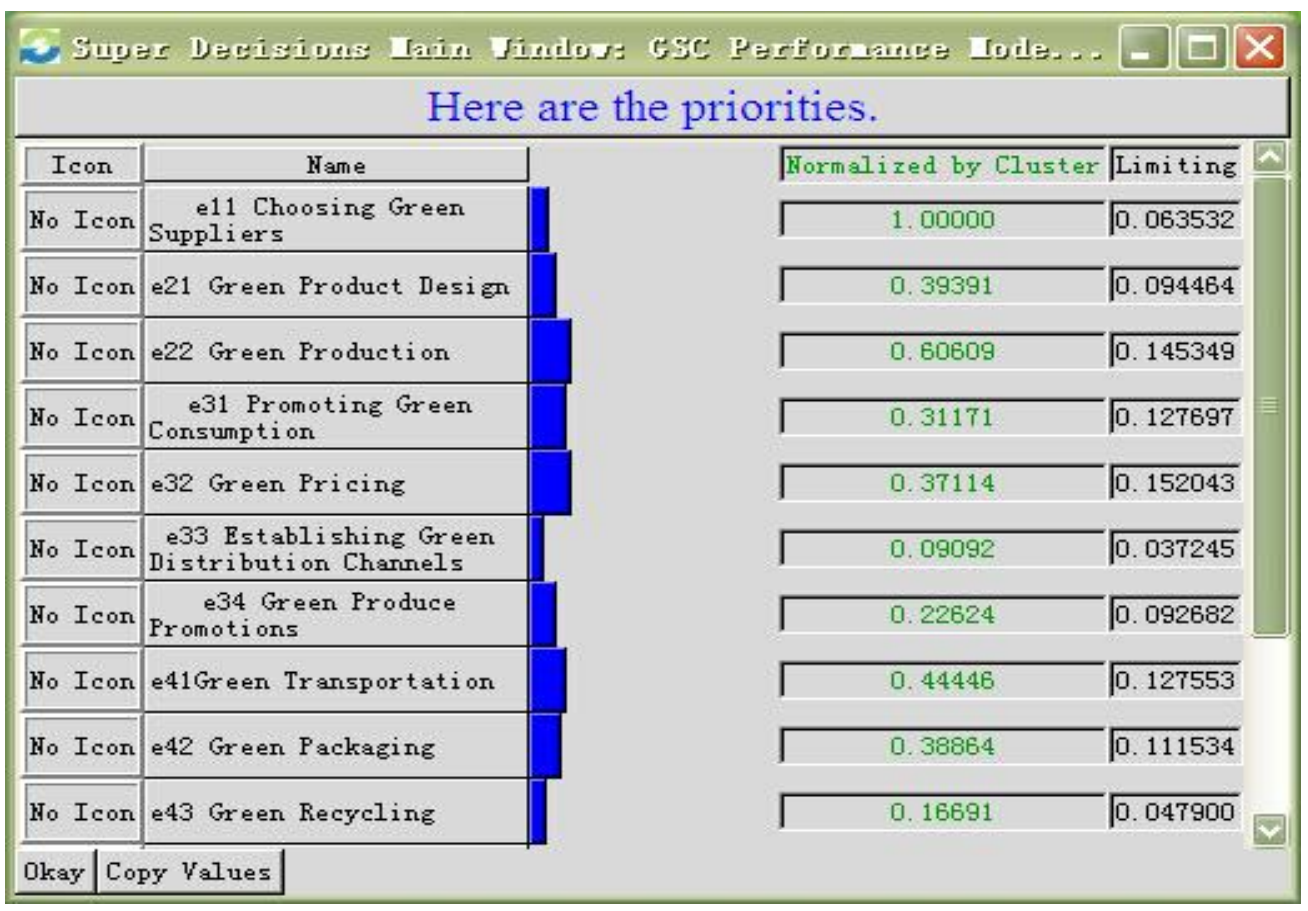

Figure 4 Priorities of enterprise green behaviors.

\section{Mean Value of the Priorities}

We dealt with the remaining nine personal judgment matrix date in the same way, and calculated the mean value of the priorities. The final result is shown in the Figure 5. 


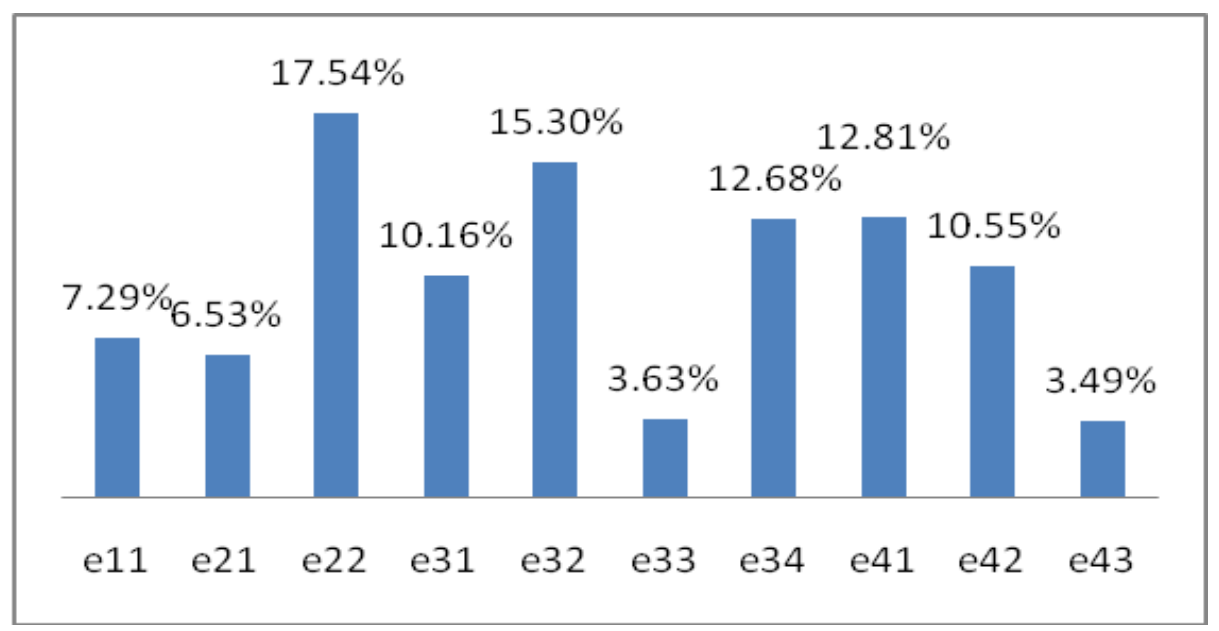

Figure 5 Mean Value of the Priorities.

\section{Analysis and Suggestions}

From the final result, we can Figure out that Green Production, Green Pricing, Green Promotional Activities and Green Transportation play the most important roles in green supply chain management efficiency. While the establishment of Green Distribution Channels and Green Recycling have a negligible effect. The reasons may be as follows.

Firstly, Guangxi manufacturing industries contain automobile, steel, nonferrous metals, petrochemicals, chemicals, building materials, papermaking, sugar, machinery as the main manufacturing industries. So we can see that all these manufacturing industries are the heavy-polluting ones. Therefore, green manufacturing is taken priority in the green supply chain management to reduce negative impact on environment.

Secondly, Green pricing and Green Promotional Activities have the greatest priority in Green Marketing Behaviours, while the establishment of Green Distribution Channels has little impact. This is caused by the underdevelopment current situation of green supply chain manufacturing in Guangxi. Most companies still act on their own way, supply chains are still fragmented, the integrative development concept of supply chains has not formed yet. So the manufacturing industries of Guangxi fail to integrate their node enterprises on their distribution channels. Companies are more likely to concern about their own interests, and market their product by a bitter domestic price wars and promotions.

Thirdly, Green Recycling has the minimal impact. It is because the development of manufacturing green supply chain in Guangxi is very slow and at a low level. The companies are more likely to focus on the systems establishment of manufacture and marketing, while look down upon the impact of Recycling on economy, environment and consumer welfare criterions.

On the basis of the analysis above, several managerial implications can be concluded as following.

Firstly, the government should play an important role in Rewarding and punishing. In the current situation, the implementation of green supply chain Management in manufacturing is inefficient. It is because the cost of implementing green supply chain to improve the environmental performance is much higher than the one of paying for the contamination, which is the result of lacking of relevant laws and supervision system. So the government should take a step to fulfil the legislation, punish the illegal polluting enterprises with a heavy penalty on the one hand. On the other hand, the government should establish the appropriate compensation mechanism and environmental subsidy system to praise the enterprises that are do well in environmental protection management. Only in these ways, can the application of green supply chain management to Guangxi manufacturing industries be encouraged.

Secondly, Guangxi manufacturing industries should cooperation with each other inter and throughout the industries to promote the development of green supply chain management. One of the innovative ways is to establish the green supply chain management business alliance between the enterprises and industries. Not only can it share information, benefit and risk, but also it would promote the business philosophy of green supply chain management. 
Thirdly, Guangxi manufacturing enterprises should have an innovative spirit and proactive strategic foresight. They must have the idea that green supply chain practices will greatly increase the core competitiveness of their enterprises with the popularity of Green Consumption awareness. What they should do is to pay more attention to the affect of Green Recycling and the establishment of Green Distribution Channels in the entire green supply chain system. Just as what the Buckets Effect says, any one shortcoming will lead to lower overall performance [7]. The managers must understand that the competitions should be in the middle of the supply chain, but not in the middle of the enterprises in twenty-first century.

\section{Acknowledgement}

We sincerely thank the guest editors and the anonymous referees for their valuable suggestions and comments. This research is supported by the Ministry of education of Humanities and social science research projects (No.10YJA630162) and the Guangxi Department of education research project (No.YB2014217).

\section{References}

[1] Handfield R. B., Green supply chain: Best Practices from the Furniture Industry. Proceedings, Annual Meeting of the Decision Science Institute USA, (3), pp.1295-1297, 1996.

[2] Walton V. S., Hardfield R. B. \& Melnyk S. A., the Green supply chain: Integrating Suppliers into Environmental Management Process. International Journal of Purchasing and Materials Management, 4, pp.2-10, 1998.

[3] B. Dan, F. Liu. The Study on Green supply chain and its Architecture. Mechanical Engineering of China, 11(11), pp.1232-1234, 2000. (In Chinese)

[4] Sarkis, J. A., Strategic Decision Frame Work for Green supply chain Management. Journal of Cleaner Production, 11, pp.297-409, 2003.

[5] Berry, M.A., Rondinelli D.A., Proactive Corporate Environmental Management: A New Industrial Revolution. Academy of Management Executive, 12(2), pp.38-50, 1998.

[6] Z. Y. Hu, S. M. Tan \& Y. Peng, Intelligent Computing Assessment and Application Basing on ANP Super Decisions Software. Computer Engineering and Design, 14(27), pp.2575-2577, 2006. (In Chinese)

[7] Wang Ying-luo, Wang Neng-min, Sun Lin-yan. The Basic Principles of Green Supply Chain Management. Chinese Engineering Science, 5(11), pp.82 87, 2003. (In Chinese) 